Saudi Journal of Medical and Pharmaceutical Sciences

Abbreviated Key Title: Saudi J Med Pharm Sci ISSN 2413-4929 (Print) |ISSN 2413-4910 (Online) Scholars Middle East Publishers, Dubai, United Arab Emirates Journal homepage: https://saudijournals.com/sjmps

\title{
Sebaceous Carcinoma of Eyelid: Case Report
}

\author{
Karmoun S*, Amhoud K, Belaydi W, Elmarzouqi B, Elhassan A, Berraho A
}

Service d'ophtalmologie B, Hôpital des spécialités de Rabat, Morocco

\begin{tabular}{ll}
\hline DOI: $10.36348 /$ sjmps.2020.v06i08.008 & | Received: $10.08 .2020 \mid$ Accepted: 17.08 .2020 | Published: 29.08 .2020 \\
*Corresponding author: Karmoun Souhaila &
\end{tabular}

\section{Abstract}

Sebaceous carcinoma of the eyelid is rare. The diagnosis might be difficult because of its ability to masquerade as other periocular lesions. This paper reports a case of sebaceous carcinoma of the eyelid in a 70-year-old man. The tumor was excised and histopathological examination revealed the characteristic features of sebaceous carcinoma.

Keywords: Sebaceous carcinoma, periocular lesions, eyelid.

Copyright @ 2020: This is an open-access article distributed under the terms of the Creative Commons Attribution license which permits unrestricted use, distribution, and reproduction in any medium for non-commercial use (NonCommercial, or CC-BY-NC) provided the original author and source are credited.

\section{INTRODUCTION}

Sebaceous carcinoma of the eyelid is the fourth most common malignancy in the periocular region in the United States and the second most common malignancy in China (basal cell carcinoma is the leading cause) $[1,2]$. Diagnosis and therapy tend to be delayed because sebaceous carcinoma is often mistaken for benign entities such as chalazion, conjunctivitis, or blepharitis [3]. The most common treatment for eyelid carcinomas is surgical resection with frozen section examination for margin control, but exenteration may be needed when there is orbital invasion. Adjuvant radiotherapy may be needed in patients at high risk for local recurrence.

\section{Case Report}

A 70-year old man consulted his ophthalmologist for a painless left ptosis associated with a tumefaction of the upper-eyelid. He had neither oculomotor disorders nor decreased visual acuity. He was refered to our clinic 6 months later; we noticed a worsening of the ptosis up to visual axis. Visual acuity was steady and the examination of the right eye was normal (Figure $1 \&$ 2). Orbital scanner has objectified a palpebral mass without periorbital infiltration. A conservative surgery was suggested with palpebral reconstruction. The diagnosis was confirmed with histopathological examination.

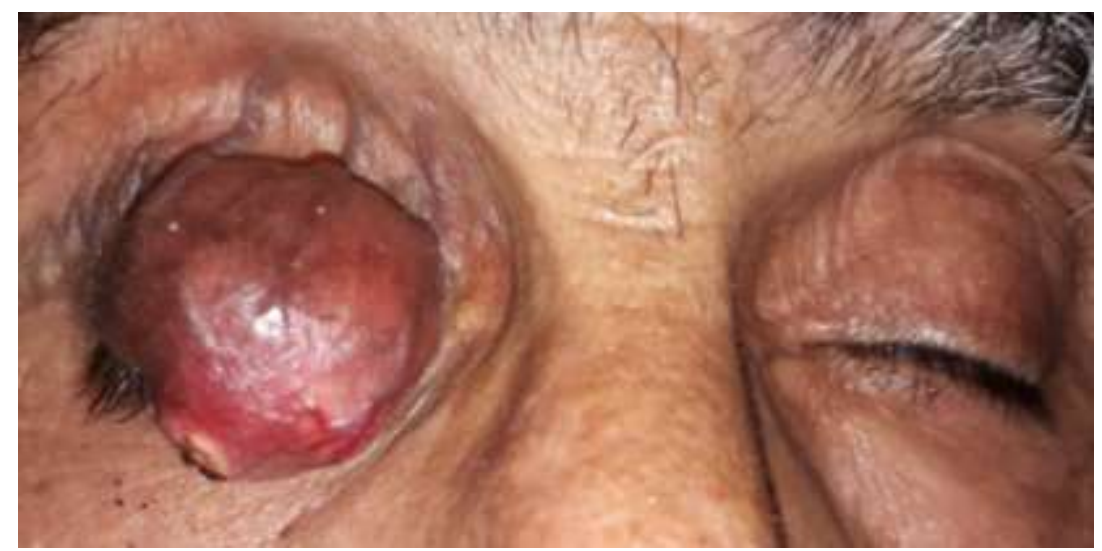

Fig-1: Sebaceous carcinoma of the left upper lid presenting as a firm, nodular, and non-tender mass 


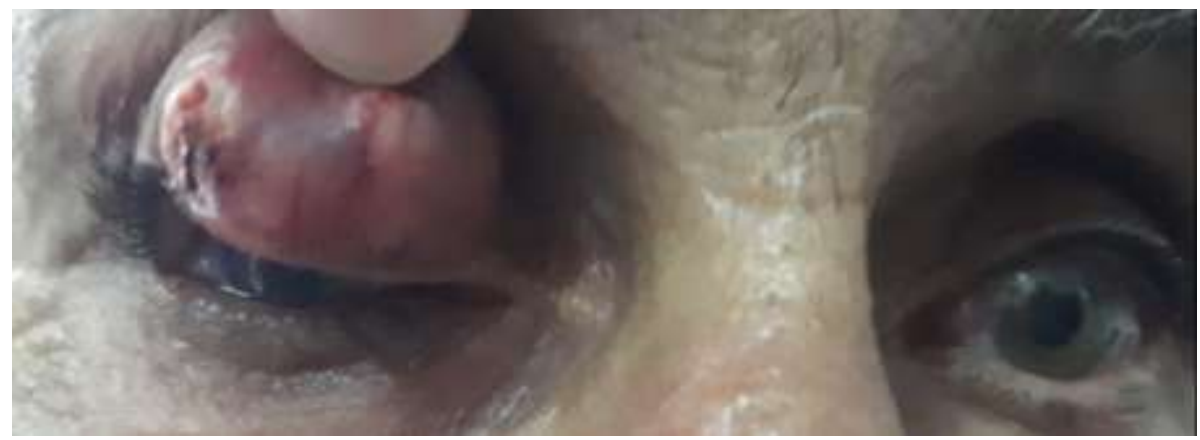

Fig-2: Sebaceous carcinoma of the left upper lid

\section{DISCUSSION}

Sebaceous carcinoma is an uncommon skin tumor which accounts for less than $1 \%$ of malignancies of the skin [4]. It occurs most frequently on the eyelids, where it comprises $4.7 \%$ of malignant epithelial tumors [5]. The incidence on the eyelid is subject to considerable geographical variation.

The median age of patients at diagnosis is 63 years [1, 3-5]. Sebaceous carcinoma of the eyelid in younger patients is apparently a rare event and, not infrequently, appears to be associated with prior radiotherapy $[6,7]$.

The tumor originates in the upper lid more often than in the lower lid. The clinical diagnosis of sebaceous carcinoma may be difficult, partly because it is rarely encountered and partly because of its propensity to simulate other eyelid lesions [2, 8, 9]. Chalazion, followed by blepharo-conjunctivitis, was the most common misdiagnosis, with other benign and malignant neoplasms also causing significant problems.

In exceptional patients the presenting sign is enlarged cervical lymph nodes, the usual primary lid lesion being inconspicuous and easily overlooked [1].

These diagnostic difficulties must be accepted and emphasise the importance of biopsies in uncertain and suspicious inflammatory states which fail to respond to appropriate treatment [10-12]. A full thickness eyelid biopsy, combined with conjunctival biopsies in certain cases, is the appropriate approach. The importance of histological examination of all suspicious chalazia must also be stressed

Adequate therapy requires wide excision of the lesion with a tumor free margin of at least $4 \mathrm{~mm}$. Frozen section control and Mohs' technique should only be employed in specialised centre with experienced ophthalmic pathologists, as these methods may alter the histological appearance of sebaceous carcinoma [13, 14]. Correct therapy in patients with multifocal tumors and extensive pagetoid spread through the conjunctiva is exenteration. Patients must be followed up at short intervals postoperatively as the tumor has a fast growth potential. Adequate follow up includes meticulous inspection of the local site. Palpation of the pre-auricular, sub-mandibular, and neck lymph nodes is mandatory.

\section{CONCLUSION}

Sebaceous carcinoma of the eyelid may arise from the diverse sebaceous glands of the ocular adnexa (15). Owing to its rarity and its ability to masquerade as other periocular lesions, diagnosis of the disease might be difficult [1-9]. Prognosis is still regarded as being poor compared with most other malignant eyelid tumors with a mortality second only to malignant melanoma [5, 15-17].

\section{REFERENCES}

1. Rao, N. A., Hidayat, L. C. A. A., McLean, L. C. I. W., \& Zimmerman, L. E. (1982). Sebaceous carcinomas of the ocular adnexa: a clinicopathologic study of 104 cases, with fiveyear follow-up data. Human pathology, 13(2), 113-122.

2. NI, C., Searl, S. S., Kuo, P. K., Chu, F. R., Chong, C. S., \& Albert, D. M. (1982). Sebaceous cell carcinomas of the ocular adnexa. International ophthalmology clinics, 22(1), 23-61.

3. Kass, L. G., \& Hornblass, A. (1989). Sebaceous carcinoma of the ocular adnexa. Survey of ophthalmology, 33(6), 477-490.

4. Warren, S., \& Warvi, W. N. (1943). Tumors of sebaceous glands. The American journal of pathology, 19(3), 441-459.

5. Doxanas, M. T., \& Green, W. R. (1984). Sebaceous gland carcinoma: review of 40 cases. Archives of Ophthalmology, 102(2), 245249.

6. Bhalla, J. S., Vashisht, S., Gupta, V. K., \& Sen, A. K. (1991). Meibomian gland carcinoma in a 20year-old patient. American journal of ophthalmology, 111(1), 114.

7. Schlernitzauer, D. A., \& Font, R. L. (1976). Sebaceous gland carcinoma of the eyelid: Following radiation therapy for cavernous hemangioma of the face. Archives of Ophthalmology, 94(9), 1523-1525. 
8. Wright, P., Collin, R. J., \& Garner, A. (1981). The masquerade syndrome. Transactions of the ophthalmological societies of the United Kingdom, 101, 244-250.

9. Foster, C. S., \& Allansmith, M. R. (1978). Chronic unilateral blepharoconjunctivitis caused by sebaceous carcinoma. American journal of ophthalmology, 86(2), 218-220.

10. Russell, W. G., Page, D. L., Hough, A. J., \& Rogers, L. W. (1980). Sebaceous carcinoma of meibomian gland origin: the diagnostic importance of pagetoid spread of neoplastic cells. American journal of clinical pathology, 73(4), 504-511.

11. Leibsohn, J., Bullock, J., \& Waller, R. (1982). Full-thickness eyelid biopsy for presumed carcinoma in situ of the palpebral conjunctiva. Ophthalmic Surgery, Lasers and Imaging Retina, 13(10), 840-842.

12. Putterman, A. M. (1986). Conjunctival map biopsy to determine pagetoid spread. American journal of ophthalmology, 102(1), 87-90.
13. Folberg, R., Whitaker, D. C., David, T. T., \& Nerad, J. A. (1987). Recurrent and residual sebaceous carcinoma after Mohs' excision of the primary lesion. American journal of ophthalmology, 103(6), 817-823.

14. Tenzel, R. R., Stewart, W. B., Boynton, J. R., \& Zbar, M. (1977). Sebaceous adenocarcinoma of the eyelid: Definition of surgical margins. Archives of Ophthalmology,95(12), 2203-2204.

15. Boniuk, M. (1968). Sebaceous carcinoma of the eyelid, eyebrow, caruncle, and orbit. Trans Am Acad Ophthalmol Otolaryngol, 72, 619-642.

16. Wolfe, J. T., Yeatts, R. P., Wick, M. R., Campbell, R. J., \& Waller, R. R. (1984). Sebaceous carcinoma of the eyelid: errors in clinical and pathologic diagnosis. The American journal of surgical pathology, 8(8), 597-606.

17. Rao, N. A. (1978). Sebaceous carcinoma of eyelids and caruncle: correlation of clinicopathologic features with prognosis. Ocular and adnexal tumors, 461-476. 